INDEPENDENT JOURNAL OF MANAGEMENT \& PRODUCTION (IJM\&P)

http://www.ijmp.jor.br

v. 12, n. 1, January-February 2021

ISSN: 2236-269X

DOI: 10.14807/ijmp.v12i1.1265

\title{
MULTI-CRITERIA DECISION MAKING FOR SUPPLIER SELECTION: A LITERATURE CRITIQUE
}

\author{
Hayk Manucharyan \\ University of Warsaw, Faculty of Economic Sciences, Poland \\ E-mail: hmanucharyan@wne.uw.edu.pl
}

Submission: 2/2/2020

Revision: $2 / 14 / 2020$

Accept: 2/28/2020

\section{ABSTRACT}

In contemporary supply chain management, a company's performance is largely dependent on its strategic choice of suppliers. The complexity of supplier evaluation and selection is driving the development of novel support techniques and their integration into multi-criteria decision-making processes. This review identifies the most prevalent approaches in the supply chain management literature (1998-2018), analyzes the strengths and weaknesses of these approaches, and discusses the most popular supplier selection attributes. The non-conventional, emerging methods in domain literature are also discussed, and future research directions are proposed. Supplier selection approaches are classified into individual, integrated, and non-conventional approaches. To overcome the limitations associated with these tools when used individually, most of the published works have used integrated techniques, among which integrated fuzzy and analytic hierarchy process methods are most popular. We conclude that while some of the methodologies are common, the more nonconventional approaches, such as market utility-based models, are rarely used in the supplier selection literature, leaving much opportunity to further develop these less-used approaches and, ultimately, aid decision-makers in supply chain management.

Keywords: Supply chain management; supplier selection; vendor selection; multi-criteria decision-making; literature review. 
DOI: 10.14807/ijmp.v12i1.1265

\section{INTRODUCTION}

In recent decades, good supplier selection has grown in importance. During the late $20^{\text {th }}$ century, many companies in the manufacturing and services industry began collaborating with their suppliers to improve organizational performance, reduce purchasing risk, increase their competitiveness, maximize value to the buyer, and establish long-lasting relationships along the supply chain network (Chen et al., 2006).

Over time, the supplier selection problem has morphed from a single-criterion costbased approach to complex scenarios, where multiple criteria are considered by decisionmakers. The selection process involves consideration of qualitative and quantitative factors to select the best possible suppliers, which improves business competitiveness and sustainability.

Aiming to develop long-lasting supplier relationships, contemporary strategies for supplier selection consider various factors, including cost reduction, quality management practices, quantity, capacity, financial strength, delivery, research and development capabilities, technology and innovation levels, attitude, performance, communication, and codesign capabilities (Macioł et al., 2013).

Given its strategic importance and complexity, supplier selection can be challenging, involving a large number of tangible and intangible criteria, decisions regarding single vs. multi-sourcing, multiple industry-specific models, the location factor, and sustainability issues.

Although the process of supplier selection can be arduous, consuming a significant amount of time and resources, when done well, it can be greatly beneficial for a firm (Jayshingpure et al., 2016). Hence, a trade-off between qualitative and quantitative factors is essential in selecting a potential supplier (Tahriri et al., 2008).

Various multi-criteria decision-making tools have been developed to support complex decisions. Many of these have been applied to the supplier selection problem. The existing literature deploys tools [such as the analytic hierarchy process, the fuzzy set theory (FST), data envelopment analysis, and goal programming (GP)] to support supplier evaluation and selection. In addition, there are integrated approaches available for those tools, which aim to overcome the limitations associated with these approaches when used in isolation (Kontis \& Vrysagotis, 2011).

Multiple literature reviews of supplier selection have been published. Jain, Wadhwa, and Deshmukh (2009) reviewed the main approaches to the supplier selection problem published before 2007. Ho et al. (2010) have analyzed multi-criteria decision-making 
DOI: 10.14807/ijmp.v12i1.1265

approaches for supplier selection based on journal articles from 2000 to 2008. These authors focused on identifying the most popular approaches, most important supplier attributes, and inadequacies in existing approaches.

Chai et al. (2013) provided a systematic review of 123 journal articles published between 2008 and 2012. Bhutta and Huq's (2002) review included 154 articles from 68 journals and was focused on the impact of information technologies on supplier selection. Also, there has been a tendency towards reviewing supplier selection from a sustainability perspective and analyzing green supplier selection (Govindan et al., 2015; Igarashi et al., 2013).

However, most reviews require an update as there have been significant developments in supplier selection methodologies and techniques over the last several years. Also, the list of relevant supplier attributes continues to expand, and some of the recent studies have evaluated suppliers based on a broader range of criteria, including globalization, development of ecommerce, and changes in technology. Moreover, none of the existing supplier selection literature reviews include non-conventional, emerging techniques, such as market utility-based approaches.

Here we provide an extended review of multi-criteria decision-making approaches for supplier evaluation and selection published between 1998 and 2018, which summarizes individual, integrated, and non-conventional methods. Based on the 177 journal articles studied, the following research questions are examined:

a) What are the most prevalent multi-criteria decision-making approaches for supplier selection in the operations management literature? What are the main inadequacies and limitations of these approaches?

b) What are the most commonly identified supplier selection criteria? How has the list of criteria changed in recent years?

c) What non-conventional approaches have been applied to the supplier selection problem, and how could those techniques be further developed?

\section{REVIEW METHODOLOGY}

The approach used when preforming this review is outlined in Figure 1. First, we searched for relevant publications within the SpringerLink, Elsevier's ScienceDirect, IEEE Xplore, ProQuest, Emerald, and Meta-Press databases. Articles including 'supplier selection', 'vendor selection', 'supply chain management', or 'multi-criteria decision-making' as 
DOI: 10.14807/ijmp.v12i1.1265

keywords were selected. The scope of this review was limited to journal articles and conference papers published between 1998 and 2018 (including those pre-published online during 2018, and subsequently published in a 2019 journal volume).

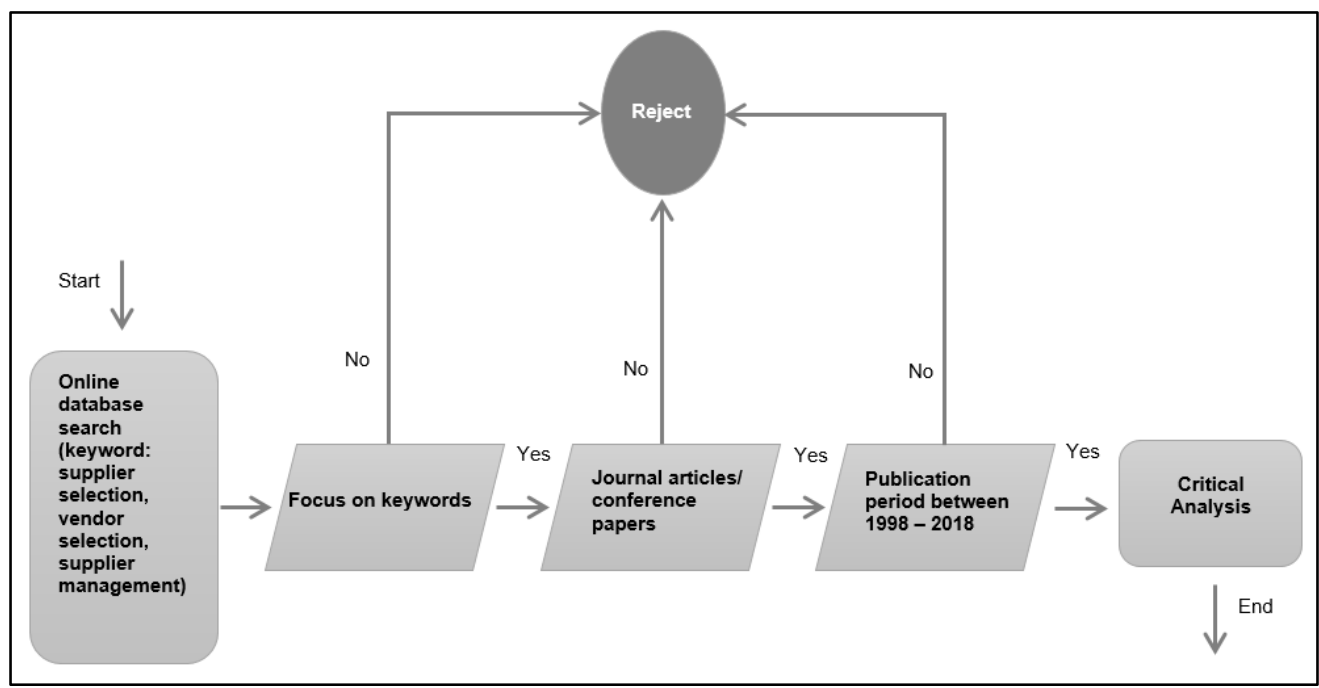

Figure 1: The article selection process.

One-hundred-seventy-seven articles that met our inclusion criteria were identified. These articles can be classified as reporting individual approaches (including decision support systems and supplier selection modeling studies), integrated approaches [including integrated analytic hierarchy process (AHP) methods, integrated fuzzy methods, and other hybrids], or non-conventional approaches (including market utility-based models).

The year with the most published articles was $2009(n=23)$. Few relevant papers were published in the early 2000s. More than 50\% of the articles reviewed apply integrated approaches to tackle the supplier selection problem. At the same time, only 8\% of the studies address non-conventional approaches. Moreover, we found only four papers that specifically implement discrete-choice experiments to model supplier selection. The most popular publication destinations were the International Journal of Production Research, Expert Systems with Applications, European Journal of Operational Research, International Journal of Integrated Supply Management, and International Journal of Production Economics. 
DOI: 10.14807/ijmp.v12i1.1265

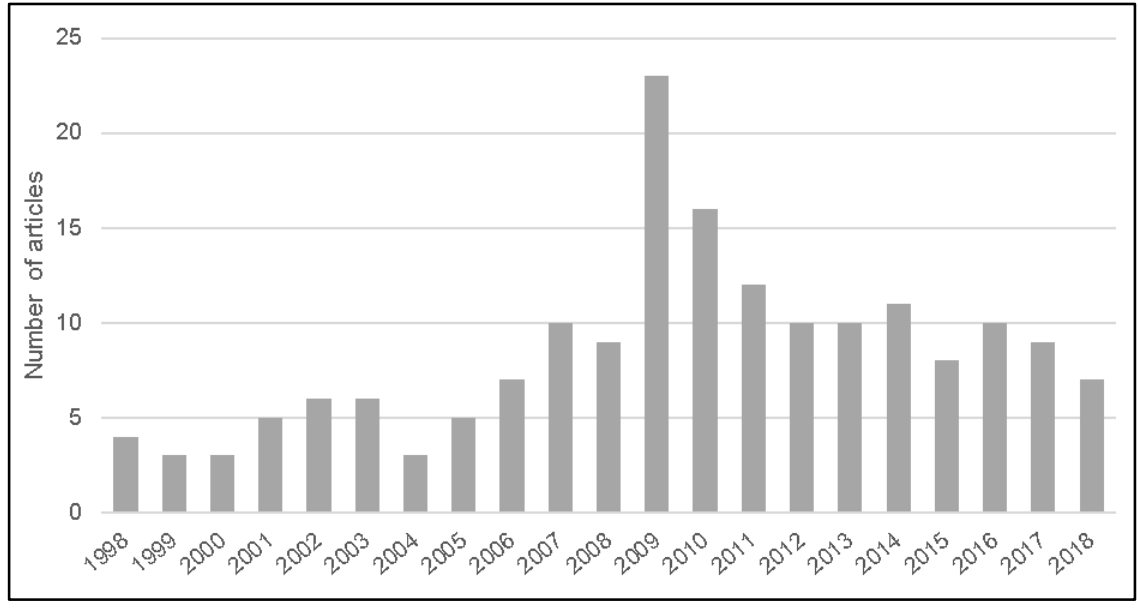

Figure 2: Chronological distribution of articles.

\section{SUPPLIER SELECTION METHODOLOGIES}

Supplier selection approaches can be classified into three categories: individual, integrated, and non-conventional approaches. The most popular individual approaches are grouped into decision support systems and supplier selection modeling papers. The most common hybrid methods include the integrated fuzzy approach and AHP. The discussion of non-conventional approaches mainly develops around market utility-based models that, so far, have been rarely used in the supplier selection literature.

\subsection{Individual approaches}

\subsubsection{Decision support systems}

As purchasing managers deal with significant difficulties when evaluating and choosing a supplier, there is a need to integrate available decision-making methods into a robust system that can assist practitioners facing multi-criteria decisions. Generally, decision support systems (DSSs) rely on computer applications to handle business data (collection, structuring, and analysis), thereby contributing to quality business decision-making. In the operations management literature, supplier selection is usually regarded as a multi-criteria decisionmaking (MCDM) problem. Therefore, many MCDM support systems have been deployed to analyze and resolve the issues related to supplier selection. The section below discusses some of the most popular DSS techniques and their applications.

\section{Analytic hierarchy process}

Perhaps the most dominant DSS in the supplier selection literature is AHP. AHP is a decision-making procedure originally developed by Saaty in the 1970s. Its primary aim is to offer solutions to decision problems in multivariate environments. AHP is used to derive ratio- 
DOI: 10.14807/ijmp.v12i1.1265

scales from both discrete and continuous paired comparisons in multi-level hierarchical structures. The process establishes decision weights for each criterion by organizing them in a hierarchical manner (Saaty, 1987; Bernasconi et al., 2010). AHP is widely applied in multicriteria decision-making, planning and resource allocation, and conflict resolution (Gaikwad et al., 2016).

Given a family of $n \geq 2$ items of a decision problem (e.g., three alternatives) to be compared for a given attribute (e.g., one criterion), in AHP, a response matrix $A=\left[a_{i j}\right]$ is constructed with the decision maker's assessments $a_{i j}$, taken to measure on a subjective ratio scale the relative dominance of item $i$ over item $j$. For all pairs of items $i, j$, it is assumed:

$$
a_{i j}=\frac{w_{i}}{w_{j}} * e_{i j}
$$

where $w_{i}$ and $w_{j}$ are the underlying subjective priority weights belonging to a vector $w=\left(w_{1}\right.$, $\left.w_{2}, \ldots, w_{n}\right)^{\prime}$, with $w_{1}>0, \ldots, w_{n}>0$, and by convention $\sum w_{j}=1$; and where $e_{i j}$ is a multiplicative term introduced to account for errors and inconsistencies in subjective judgments typically observed in practice.

The steps for the selection of best supplier through the AHP process are explained as follows:

Step 1: Identify a set of criteria and sub-criteria, then establish a hierarchical structure. The process begins by determining the set of criteria for the evaluation and selection of suppliers. After the selection of criteria, the AHP hierarchy is constructed.

Step 2: Constructing a pair-wise comparison matrix with a scale of relative importance. Pair-wise comparison of the attribute is made using the scale given in Table 1.

Table 1: Measurement scales.

\begin{tabular}{lll}
\hline Intensity importance & Definition & Explanation \\
\hline 9 & Absolute importance & $\begin{array}{l}\text { The evidence favoring one activity } \\
\text { over another is of the highest possible } \\
\text { order of affirmation. } \\
\text { An activity is favored very strongly } \\
\text { over another. }\end{array}$ \\
5 & Very strong importance & $\begin{array}{l}\text { Experience and judgment strongly } \\
\text { favor one activity over another. } \\
\text { Experience and judgment slightly } \\
\text { favored one activity over another. } \\
\text { Two activities contribute equally to the } \\
\text { objective. }\end{array}$ \\
& Weak importance & When compromise is needed. \\
\end{tabular}


DOI: 10.14807/ijmp.v12i1.1265

Pair-wise comparisons express the relative importance of one item versus another in meeting a goal or criterion. An attribute compared with itself is always assigned a value of 1 ; therefore, all main diagonal entries of the pair-wise comparison matrix are 1.

$A=\left[a_{i j}\right]=\left[\begin{array}{cccc}1 & a_{12} & \ldots & a_{1 m} \\ a_{21} & 1 & \ldots & a_{2 m} \\ \ldots & \ldots & \ldots & \ldots \\ a_{m 1} & a_{m 2} & \ldots & 1\end{array}\right]=\left[\begin{array}{cccc}1 & a_{12} & \ldots & a_{1 m} \\ 1 / a_{12} & 1 & \ldots & a_{2 m} \\ \ldots & \ldots & \ldots & \ldots \\ 1 / a_{1 m} & 1 / a_{2 m} & \ldots & 1\end{array}\right]$

where $a_{i j}$ and $a_{j i}=1 / a_{i j} ; i, j=1,2, \ldots \ldots, m$.

Step 3: Finding the relative normalized weight or set of priorities of each attribute by calculating the geometric mean (GM). In the GM approximation approach, the GM of the elements in each row of the square decision matrix is computed. This method is used to normalize the vector so that its elements add to unity.

Step 4: Analysis of consistency in decision-making. Every pair-wise comparison matrix should pass the consistency test. To measure the degree of consistency, Saaty (1980) suggested the consistency index, which is represented by equation (2).

$C I=\frac{\left(\lambda_{\max }-n\right)}{(n-1)}$

For each $n \times n$ pair-wise comparison matrix $A$, it is possible to calculate the eigenvalue $\lambda_{\max }$ and the eigenvector $w\left(w_{1}, w_{2}, \ldots, w_{n}\right)$ using the theory of eigenvector shown in equation (3).

$\left(A-\lambda_{\max } * 1\right) w=0$

To employ this index, comparisons can be made with a random index (RI) using the consistency ratio (CR) represented by equation (4).

$C R=\frac{C I}{R I}$

Usually, a CR value of 0.1 or less is considered acceptable and reveals cognizant judgment that could be attributed to the knowledge of the analyst. Followed by supplier evaluation, order allocation is done.

AHP has been extensively employed in the operations management literature to address supplier selection issues. Bali and Amin (2017) use an integrated model of AHP and linear programming for supplier evaluation and selection. Suppliers are selected based on multiple 
DOI: 10.14807/ijmp.v12i1.1265

criteria and ranked based on their performance using the AHP technique. This is then used to determine the optimal quantity to be procured from each of the best-ranked suppliers.

\section{Fuzzy set theory}

Fuzzy logic is an alternative approach to computing. Rather than applying the typical 'true or false' (1 or 0) Boolean logic, fuzzy logic is based on 'degrees of truth'. Fuzzy logic is a way of processing data by allowing partial set membership instead of crisp set membership or non-membership. Fuzzy logic has been extended to handle the concept of partial truth, where the truth value can range between completely true and completely false.

Moreover, when linguistic variables are used, these degrees can be managed by specific functions. Fuzzy logic has proven to be an excellent choice for many control system applications from small, hand-held products to large computerized process control systems. The fuzzy inference system (FIS) uses FST to map inputs to outputs. The FST was presented by Zadeh (1965) in his seminal paper 'fuzzy sets' in information and control. In FST, fuzzy numbers are used to deal with ambiguity in decision-making. A fuzzy number is a special set

$F=\left\{\left(x, \mu_{F}(x)\right), x \in R\right\}$

where $x$ is the value on the real line $R_{1}:-\infty<x<+\infty$ and $\mu_{F}(x)$ is a continuous mapping from $R_{1}$ to the close interval [0,1]. A triangular fuzzy number (TFN) can be donated as $M=(l$, $m, u)$, its membership function $\mu_{M}(x): R \rightarrow[0,1]$ is equal to:

$\mu_{m}(x)= \begin{cases}\frac{x}{m-l}-\frac{l}{m-l}, & x \in[l, m] \\ \frac{x}{m-u}-\frac{u}{m-u}, & x \in[m, u] \\ 0, & \text { Otherwise }\end{cases}$

where $l \leq m \leq u, l, m$, and $u$ are the lower, mode, and upper values of the support of $\mathrm{M}$, respectively. When $l=m=u$, it is a non-fuzzy number by convention (CHANG, 1996). The main operational laws for two triangular fuzzy numbers $M_{1}$ and $M_{2}$ are as follows (KAUFMANN, 1991): 
$M_{1}+M_{2}=\left(l_{1}+l_{2}, m_{1}+m_{2}, u_{1}+u_{2}\right)$,

$M_{1} \oplus M_{2}=\left(l_{1} l_{2}, m_{1} m_{2}, u_{1} u_{2}\right)$,

$\lambda \oplus M_{1}=\left(\lambda l_{1}, \lambda m_{1}, \lambda u_{1}\right), \lambda>0, \lambda \in R$

$M_{1}^{-1}=\left(1 / l_{1}, 1 / m_{1}, 1 / u_{1}\right)$

Figure 3 shows the membership function of a triangular fuzzy number. In Figure 3, the numbers $M=(l, u)$ represent lower and upper values of the fuzzy number $M$, respectively, whereas $m$ is the middle value of $M$.

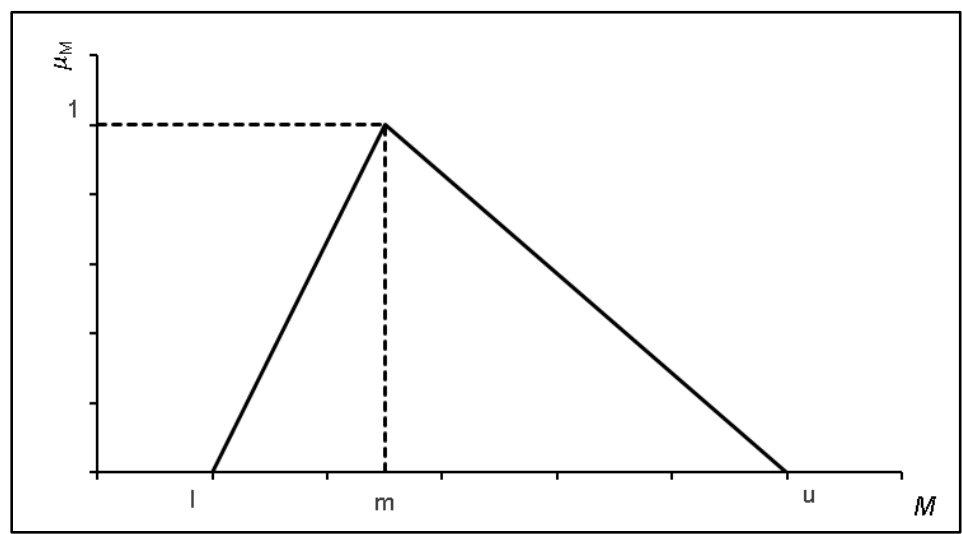

Figure 3: Triangular membership function.

Only a few operations management studies report the use of the Fuzzy Logic Toolbox in multi-criteria decision-making. Paul and Azeem (2010a) designed a model for selecting the optimal shift numbers, considering inventory information, customer requirements, and machine reliability using fuzzy logic. The model was developed for any kind of manufacturing company where shift periods affect profit and cost.

Fuzzy control is used to optimize the number of shifts under the constraints of raw materials, delivery deadline, demand, and machine breakdown, among other factors. Paul and Azeem (2010b) used fuzzy sets to tackle uncertainties inherent in actual flow shop scheduling problems to minimize work-in-process inventory. Zemkova (2011) used fuzzy sets in the performance evaluation of employees in a company, where a multi-criteria evaluation was utilized.

\section{Compromise programming: TOPSIS, VIKOR}


DOI: 10.14807/ijmp.v12i1.1265

The foundation of compromise programming methods was established in the 1970s. As typical compromise methods, TOPSIS and VIKOR are implemented based on the aggregating function that shows the proximity to the ideal solution. The key difference between the two techniques is that TOPSIS uses linear optimization to eliminate the units of criteria function, whereas VIKOR is based on vector normalization. Mirahmadi and Teimoury (2012) used fuzzy VIKOR, a fuzzy compromise solution, to rank and select suppliers. Fuzzy logic and trapezoidal fuzzy numbers were utilized to overcome the ambiguity of the evaluation process.

\section{Other DSS methods}

In recent decades, researchers have applied other DSS techniques to tackle the supplier selection problem, including multi-objective programming, case-based reasoning, and data envelopment analysis. Karpak et al. (2011) discussed the role of visual interactive GP (VIG) in solving multi-objective problems pertaining to vendor selection. Application of VIG was discussed for two situations: for allocation of a single product to multiple suppliers; and for multi-renewal problems related to vendor selection and order allocation.

\subsubsection{Supplier selection modeling papers}

While it is unlikely that a single supplier can excel in all the evaluation criteria, it is always desirable for purchasers to select a vendor that performs well in most dimensions. Nevertheless, manufacturing firms must trade-off between price, quality, and other attributes when choosing a supplier. To address these complex decision-making situations, a variety of supplier evaluation and selection models have been developed in recent years.

Ávila et al. (2012) identified five broad selection criteria for supplier selection: quality, financial, synergies, cost, and production system. These authors proposed a model of linear weighting to reflect the significance of all the factors based on a customized survey. The model has a hierarchical structure and can be applied with AHP or value analysis. The authors aimed to provide a selection reference model that could serve as a guide for decision-making during supplier selection.

Kar (2009) modeled supplier selection in e-procurement as a multi-criteria decisionmaking problem. Supplier selection criteria and constraints are modeled using fuzzy logic, which is further modeled as a multi-objective decision-making process by combining neural networks and the analytic hierarchy process. Suppliers are then classified as suitable suppliers or unsuitable suppliers. 
DOI: 10.14807/ijmp.v12i1.1265

Yang et al. (2007) applied polychromatic sets to discuss the supplier selection problem and describe the relevant factors. Supplier performance is evaluated based on delivery, cost, flexibility, quality, and reliability. Masella and Rangone (2000) proposed a contingency approach for supplier selection depending on the time frame and the content of co-operative customer/supplier relationships.

\subsection{Integrated approaches}

\subsubsection{Integrated AHP approaches}

Hassan et al. (2015) develop a hybrid model using AHP, artificial neural networks (ANNs), and relative reliability risk index (R3I) to score suppliers based on their performance. AHP is implemented to rank suppliers based on criteria using pairwise comparison, and the output of AHP is used in the ANN model for comparison. Leanness, agility, resilience, and greenness paradigms are used in this paper as new criteria for evaluating and selecting the best supplier. Silva and Schramm (2015) developed a multi-criteria DSS model, PROMETHEE II, for supplier selection. PROMETHEE II is applied to construct a ranking of suppliers according to the inputs from stakeholders, then the robustness of the model is analyzed to check its suitability for the construction industry.

Scott et al. (2015) proposed an integrated DSS model using modified AHP and quality function deployment (QFD) for supplier selection and order allocation in a multi-criteria and multi-stakeholder business environment (e.g., the bioenergy industry). A conceptual model was developed to identify supplier characteristics and stakeholder requirements, which was used to process supplier evaluation. QFD was used for various stakeholders to express their requirements and to translate them into multiple comparable evaluation criteria for supplier selection.

The most important information that QFD provides is the weights of evaluating criteria, which are derived from the importance ratings of stakeholder requirements together with the relationship weightings between stakeholder requirements and evaluating criteria. Generally, both importance ratings of stakeholder requirements and relationship weightings are arbitrarily determined by the decision-makers. This might result in a certain degree of inconsistency and, therefore, degrade the quality of decisions made. Hence, AHP is used to evaluate these consistently.

\subsubsection{Integrated fuzzy approaches}


DOI: 10.14807/ijmp.v12i1.1265

Fuzzy AHP (FAHP) is an integrated approach that combines FST and AHP. The first FAHP study was proposed by van Laarhoven and Pedrycz (1983), which compares the fuzzy ratio described by a triangular fuzzy number. These authors used the framework of the practical region of relative weight. Fuzzy consistency was determined as the existence of relative weights within the region. Then, the highest/lowest set ranking method was developed to obtain a clear ranking from the global fuzzy weight. The next step of FAHP was introduced by Chang (1996), who used the triangular fuzzy number to create a pairwise comparison scale of FAHP.

Lee et al. (2009) used fuzzy multiple GP to select suppliers. FAHP was first applied to analyze the importance of multiple factors by incorporating expert opinions. These factors included cost, yield, and the number of suppliers. Multi-choice GP was then used to consider the limits of various resources and formulate the constraints.

Kumar et al. (2004) proposed a fuzzy GP approach for vendor selection in the supply chain. The vendor selection process was formulated as a fuzzy mixed integer GP vendor selection problem that included three primary goals: minimizing the net cost, minimizing the net rejections, and minimizing the net late deliveries. An illustration from a realistic situation was included to demonstrate the effectiveness of the model.

\subsubsection{Other integrated approaches}

\section{Compromise programming}

Multiple studies have suggested new methods based on TOPSIS and VIKOR, or even combining these with other MCDM techniques. Shahroudi and Tonekaboni (2012) developed a TOPSIS methodology to evaluate suppliers. Bhutia and Phipon (2012) have proposed an integrated approach to evaluate and rank suppliers using AHP and TOPSIS. Shemshadi et al. (2011) extended the VIKOR method with a mechanism to extract and deploy objective weights based on the Shannon entropy concept. These authors also presented a numerical example to illustrate an application of the proposed method.

\section{Goal programming}

GP is one of the most popular mathematical programming techniques used in the operations management literature. GP can be considered an extension of linear programming that is used to deal with multiple and conflicting measures. Each of the measures is given a goal value to be achieved. Erdem and Göçen (2012) proposed a DSS model for supplier selection and order allocation. Initially, an AHP model was developed for qualitative and quantitative evaluation of suppliers. 
DOI: 10.14807/ijmp.v12i1.1265

Based on these evaluations, a GP model was developed for order allocation among suppliers. The models were integrated into a DSS that provides a dynamic, flexible, and fast decision-making environment. Inputs from suppliers were used for their evaluation using AHP, and based on criteria from buyers, suppliers were weighed or graded. Similarly, order goals from buyers were taken as inputs for order allocation using GP.

\section{ANP, LP, DEMATEL, and PROMETHEE}

Xiaobing and Qiang (2007) developed a vendor selection model based on procurement cost and delivery time. A mathematical model based on an adaptive genetic algorithm was later developed for multi-constraint supplier selection, showing good validity and efficiency. $\mathrm{Xu}$ and Xiang-Yang (2007) have proposed a multiphase supplier selection model based on supplier development orientation. The model has three phases: pre-selection of vendor using DSS PROMETHEE, evaluation of supplier using ANP, and supplier development using relationship value estimation criteria.

Lin et al. (2011) used the enterprise resource planning (ERP) system in the push and pull concept for supplier selection based on resource and profit creation. The analytic network process (ANP) and technique for order preference by similarity to ideal solution (TOPSIS) were used to calculate the weights and rank suppliers. Linear programming (LP) effectively allocated order quantity to each vendor for real-time application in the electronics industry. Dalalah et al. (2011) presented a hybrid fuzzy model (modified DEMATEL, modified TOPSIS model) for group multi-criteria decision-making in supplier selection. The modified DEMATEL deals with the influential relationship between evaluation criteria and divides them into cause and effect groups. The modified TOPSIS evaluates the criteria against each alternative using a fuzzy distance measure.

\section{Integrated Delphi approaches}

The Delphi method has been widely applied in social sciences as a tool for screening criteria and finding customized criteria and is attractive because of its ability to guide group judgments toward a final decision (Mckenna, 1994). In the supplier selection literature, the Delphi method has been applied in combination with other approaches. Liao (2010) used the Delphi technique to obtain the criteria, transferred these into the Taguchi loss function, and then selected the best supplier in a food manufacturing factory in combination with AHP-based weights. 
DOI: 10.14807/ijmp.v12i1.1265

To identify the most appropriate third-party logistics provider for the Iranian automobile industry, Yazdi et al. (2018) integrated three approaches: entropy, Delphi, and evaluation by an area-based method of ranking (EAMR). These authors used the Delphi method to identify the criteria, the entropy method to determine the weights of criteria, and EAMR to rank the alternatives.

Kaviani et al. (2019) proposed a hybrid multi-criteria tool to assist with decisionmaking. This tool integrates the Delphi, Shannon entropy, and evaluation based on distance from average solution (EDAS) techniques under a grey environment that introduces accurate computation, thereby overcoming the weakness in the AHP, TOPSIS, and VIKOR techniques and helping with supplier selection. There is also relevant work on applying the Fuzzy Delphi method to validate supplier selection criteria in the fuzzy environment and then using the integrated AHP plus DEMATEL approach to determine the weights and cause-effects relationships of parameters (KUMAR et al., 2018).

\subsection{Non-conventional approaches}

\subsubsection{Market utility-based approaches}

Market utility-based approaches can evaluate the relative weights of different valueadded features of suppliers in procurement decision-making processes (Ben-Akiva; Lerman, 1991; Mcfadden, 1986; Louviere et al., 2001). Some of these methods (e.g., discrete-choice analyses or DCAs) have been applied in the social sciences, including marketing, transportation planning, environmental resource economics, service design, and operations management. Examples of discrete choice and conjoint analyses in the operations management literature include product line decisions (Yano \& Dobson, 1998), optimal service design (Verma et al., 2001), and operations capacity planning (Pullman; Moore, 1999). Also, discrete choice models have been applied in a variety of operational settings (Ding et al., 2007; Victorino et al., 2005).

Although market utility-based approaches and, particularly, discrete-choice models are effective in operations management, little work has been done to integrate those techniques into the supplier selection problem. Perhaps one of the earliest and most prominent studies in this field is the discrete choice analysis performed by Verma and Pullman (1998).

These authors proposed a two-staged experimental setup. In the first stage, the participants (purchasing managers) are asked to rank supplier attributes using Likert scale questions. The second stage involves a discrete choice experiment examining the actual choice of suppliers. The authors claim that purchasing managers' stated preferences regarding the 
DOI: 10.14807/ijmp.v12i1.1265

importance of supplier selection criteria do not necessarily coincide with their actual choices. These results indicate that although managers say that quality is the most important attribute for a supplier, they actually choose suppliers based largely on cost and delivery performance.

Li et al. (2006) extended the use of DCA in the supplier selection literature by comparing the attributes of an existing supplier to that of a new supplier. These authors also extended the theoretical framework to include supplier switching inertia (they prepared individually customized discrete choice experiments asking the respondents to either switch to the new supplier or remain with the existing supplier), confirming the existence of switching inertia and, as a result, the competitive asymmetry between current and new suppliers from a demand-side perspective.

Verma et al. (2008) provided an overview of the recent advances in discrete choice modeling for applications in the service sector. These authors provided directions for designing and executing discrete choice studies for services and discussed several examples for multiple industries, including healthcare, financial services, retail, hospitality, and online services. Van der Rhee et al. (2009) explored how executives and managers trade-off amongst various competitive dimensions, such as cost, delivery performance, flexibility, and value-added service/support when selecting a supplier for raw materials, with the condition that minimum acceptable quality is guaranteed.

\subsubsection{Other emerging approaches}

Incorporating risk and uncertainty into the supplier selection problem is one of the most prominent emerging concerns in operations management literature. Micheli et al. (2009) studied the mitigation of risks in the overall supply chain using a risk-efficiency-based supplier selection approach in engineering, procurement, and construction industries. Li et al. (2015) used an agent-based simulation model to deal with supplier selection by incorporating risk scenarios under constraints based on supplier profit and customer service level.

Ebahimipour et al. (2016) examined product structure for a multi-criteria and multiproduct supplier selection problem with uncertainty. Evaluation indices are also addressed by the emerging approaches for supplier evaluation and selection. Duan et al. (2010) presented a model that uses canonical correlation discriminant analysis to provide a flexible way of determining the evaluation indices to be used for selecting suppliers. Tang et al. (2009) constructed a supplier evaluation index system for a comprehensive evaluation of suppliers by 
DOI: 10.14807/ijmp.v12i1.1265

the features of the tourism supply chain and an entropy-weighted extension matter-element model.

Amongst other non-conventional supplier selection models, the ordinal game theory approach has also been used in several applications in the last decade. The ordinal game theory approach helps two competing companies select the most suitable supplier in terms of three criteria - quality, cost, and delivery time. Kermani et al. (2012) provide a numerical example of such a game between two manufacturers.

\section{DISCUSSION}

The results of this review show that the existing multi-criteria decision-making tools provide various solutions to supplier evaluation and selection problems. To overcome the limitations and weaknesses of individual tools, researchers often integrate multiple approaches. In our review, more than $50 \%$ of the 177 papers included hybrid approaches. The prevalence of integrated methods can be attributed to the growing complexity of supplier selection and the need to further develop existing approaches while utilizing their advantages.

At the same time, around $40 \%$ of papers are still based on individual approaches, which are easy to use and do not require significant time investment. Despite the growth of nonconventional methods in recent years, such methods are addressed in only $8 \%$ of the reviewed articles. This indicates that the supplier selection domain has space for further alternative solutions. Moreover, there is a need to further test existing non-conventional methods, such as market utility-based approaches, as the current regional and industry scope is relatively limited.

One of the objectives of this paper was to determine the most frequently used approaches in supplier selection literature. The majority of the studies apply DSSs to address the challenges associated with supplier evaluation and selection. Amongst DSSs, the AHP is, perhaps, the most dominant technique (individually and when integrated with other methods).

AHP has attracted significant attention due to its simplicity and ease of use, and has been integrated with various other techniques, including FST, artificial neural network, binegotiation, data envelopment analysis, GP, grey relational analysis, and multi-objective programming. The integration of AHP with FST is especially popular given FST's ability to cope with uncertain and imprecise information.

In most reviewed articles, the decisions or judgments of decision-makers are brought out using linguistic variables with corresponding fuzzy numbers (Zouggari \& Benyoucef, 2012; Dargi et al., 2014; Xie et al., 2016). In addition, the integration of FST with other MCDM 
DOI: 10.14807/ijmp.v12i1.1265

methods provides more robust solutions by overcoming the limitations of individual approaches. For instance, ANP is used to provide weights of interdependent criteria, while suppliers are ranked using PROMETHEE (Hanane et al., 2015). Similarly, AHP is used to generate weights of evaluation criteria, and TOPSIS is used to rank alternative suppliers (Wang \& Zhou, 2011). Most of these applications use FST to address the imprecise judgments of decision-makers.

Below, the most prevalent approaches in supplier selection literature are critically analyzed, discussing their major strengths and weaknesses. DSSs, such as AHP and ANP, are commonly used to address the supplier selection problem. Since the usual structure of the problem involves a finite number of alternatives under a finite number of evaluation criteria, the use of DSSs is considered the most plausible approach (Ho et al., 2010, Yildiz \& Yayla, 2015).

AHP is widely used due to its simplicity and ease of use, but it also has limitations. Whenever faced with a large number of alternative criteria, the pairwise comparison process becomes time-consuming. If a problem involves $n$ criteria and $m$ suppliers, the total number of pairwise comparisons is $(n(n-1)+n m(m-1)) / 2$. Increasing $n, m$, or both will result in a secondorder increase in the number of evaluations to be performed by decision-makers.

Moreover, Saaty and Özdemir (2003) have noted that the number of elements to be compared in AHP should not be more than seven (or seven plus/minus two) to maintain consistency in judgments. This limitation poses a drawback to some supplier selection problems as a large number of candidate suppliers can cause problems.

The reviewed papers (Blaszczyk \& Wachowicz, 2010; Wang \& Sun, 2011; Xu et al., 2013) satisfy this requirement, except for Mukherjee et al. (2009), with ten alternative suppliers, which might raise questions about the validity of the results. Furthermore, the issue of rank reversal, raised by Forman and Gass (2001), has become a major drawback of the AHP method, which states that when an additional alternative is added, axioms of decision theories state that the ranking of the original alternatives must not be changed (prohibiting rank reversal).

However, the original AHP formulation allows for rank reversal. In supplier selection problems, this issue might pose serious implications as it can alter the rankings of candidate suppliers when a new supplier is considered. Finally, the assumption of independence among and within criteria and alternatives is also a drawback of the AHP as real-world supplier 
DOI: 10.14807/ijmp.v12i1.1265

selection problems have inherent interdependencies of criteria and/or alternatives. For instance, many studies (Wang \& Sun, 2011) use AHP assuming that cost and quality are not interdependent, whereas these two criteria are related.

While the use of ANP in supplier selection problems addresses the issue of both rank reversal and interdependence, the number of pairwise comparisons increases with the number of interdependencies introduced into the decision system. As a benefit, it reflects case-specific scenarios in supplier selection problems. As a drawback, the interdependencies might provide general insights, and their introduction to the problem might not always be valid (Yulugkural et al., 2013).

TOPSIS is also widely used as a multi-criteria decision-making tool in supplier selection problems due to its operational simplicity (Huo et al., 2011; Jiang et al., 2009; Wang \& Song, 2010). It also overcomes the 'seven plus or minus two' limitation of the AHP/ANP approaches; it can evaluate a finite large number of suppliers that reflect real-life conditions. However, the use of Euclidean distance as the basis for ranking suppliers does not consider the interdependencies of evaluation criteria. Furthermore, Madi et al. (2016) claim that TOPSIS might have issues around reliability and consistency, which can affect supplier selection.

The review of non-conventional approaches is an important part of this study. While most of the empirical articles are based on the managers' rating of the perceived importance of different supplier attributes, this group of papers studies how managers actually choose suppliers. An actual choice of supplier involves evaluating the characteristics of the suppliers based on their attributes and selecting one or more supplier(s) that best suit the needs of the firm. Market utility-based approaches, such as discrete-choice analyses, can assess the relative weights of price, quality, delivery, flexibility, and various value-added features in various managerial decision-making processes (Louviere et al., 2001).

These methods have been widely used in many social sciences, including marketing, transportation planning, environmental resource economics, service design, and operations management (Pullman \& Moore, 1999; Pullman et al., 2001; Verma et al., 2001). Examples of discrete choice and conjoint analysis in operations management include product line decisions (Yano \& Dobson, 1998), optimal service design (Verma et al., 2001), and operations capacity planning (Pullman \& Moore, 1999).

Also, Ding et al. (2007) and Victorino et al. (2005) have applied discrete choice models in a variety of operational settings. Furthermore, an emerging emphasis on incorporating 
DOI: 10.14807/ijmp.v12i1.1265

behavioral aspects into manufacturing and service operations models (Bendoly et al., 2006) suggests that future growth of discrete-choice analyses and related approaches is likely within the operations management literature.

Finally, this paper is aimed at analyzing the development of the relevance of supplier attributes and assessing the most common evaluation criteria. First, it was observed that price is not the only attribute considered when evaluating and choosing suppliers. Moreover, price is no longer the criterion with the highest perceived importance. Instead, when making decisions, factors such as quality or delivery performance are often considered. This is in line with the growing consensus that traditional single-criterion approaches based on the lowest cost are neither supportive nor robust enough.

More than $80 \%$ of the publications consider quality in supplier selection. Various quality-related attributes have been identified among the papers, such as 'acceptable parts per million', 'compliance with quality', 'quality control rejection rate', and 'end-customer rejection rate'. The second most popular criterion is delivery (slightly below $80 \%$ ). The most common attributes include 'compliance with the due date', 'fill rate', 'delivery lead time', and 'waiting time'.

Finally, more than $70 \%$ of articles mention price/cost as a key supplier selection criterion. Cost-related attributes include 'purchase price', 'logistics costs', 'cost reduction performance', 'direct cost', 'fluctuation on costs', and 'manufacturing cost'. Based on these findings, price/cost is not the most widely adopted criterion. The traditional single-criterion approach based on the lowest cost bidding is no longer supportive or robust enough in contemporary supply chain management.

Moreover, with increasing globalization, changing customer preference, speed of delivery, increased supply chain risk, increased number of suppliers, increased outsourcing, improved purchasing function, use of the Internet, increased options, and government regulation and transparency, more complex supplier attributes have been introduced since 1998, which now play key roles in purchasing decisions (Boer et al., 2001). Table 2 provides a comprehensive list of the most recent supplier rating criteria.

Table 2. Criteria for supplier selection rating system (from 1998 to 2018).

\begin{tabular}{l|rl}
\hline Supplier attribute & Frequency & Representative authors \\
\hline Quality & 143 & Verma and Pullman (1998), Lee et al. (2003) \\
Delivery & 136 & Pullman et al. (2001), van der Rhee et al. (2009) \\
Cost & 127 & Verma and Pullman (1998), Lin et al. (2005)
\end{tabular}


INDEPENDENT JOURNAL OF MANAGEMENT \& PRODUCTION (IJM\&P)

http://www.ijmp.jor.br

v. 12, n. 1, January-February 2021

ISSN: 2236-269X

DOI: $10.14807 /$ ijmp.v12i1.1265

\begin{tabular}{|c|c|c|}
\hline Supplier attribute & Frequency & Representative authors \\
\hline Financial stability & 102 & Masella and Rangone (2000), Wang et al. (2004) \\
\hline Service & 101 & Vonderembse and Tracey (1999), Lee et al. (2003) \\
\hline Communication & 97 & Louviere et al. (2000), Liao and Rittscher (2007) \\
\hline Risk management & 96 & Li et al. (2006), Karpak et al. (1999) \\
\hline Reputation and credibility & 92 & Kaplan and Sawhney (2000), Kannan and Tan (2002) \\
\hline Facilities and capacity & 86 & Karpak et al. (1999), Basnet and Leung (2005) \\
\hline Repair services & 84 & Bhutta and Huq (2002), Chan (2003) \\
\hline Promotion potential & 80 & Carter and Jennings (2004), Choy et al. (2004) \\
\hline Performance history & 72 & Liao and Rittscher (2007), Li et al. (2006) \\
\hline Quality management practices & 72 & Pullman and Moore (1999), Talluri (2006) \\
\hline Location & 70 & Sarkis and Semple (1999), Pullman et al. (2001) \\
\hline Automated storage and retrieval systems & 67 & Wang et al. (2004), Hanfield and Nichols (1999) \\
\hline Rapid prototyping techniques & 65 & Huang and Keskar (2007), Ittner and Larcker (1999) \\
\hline $\begin{array}{l}\text { Computer-aided design, manufacturing } \\
\text { and/or engineering }\end{array}$ & 64 & $\begin{array}{l}\text { Gonzàlez et al. (2004), Eltantawy et al. (2003), } \\
\text { Vonderembse and Tracey (1999) }\end{array}$ \\
\hline Automated handling & 60 & Ding et al. (2007), Choy et al. (2003) \\
\hline Integration capabilities & 56 & Chen et al. (2006), Carter and Jennings (2004) \\
\hline Experience & 51 & Cakravastia and Takahashi (2004), Chan (2003) \\
\hline Management and organization & 49 & Amoako-Gyampah and Acquaah (2008) \\
\hline Insurance and warranty policies & 48 & Alidrisi (2014), Amin and Razmi (2009) \\
\hline Environmental and social responsibility & 46 & Amid et al. (2009), Dai und Blackhurst (2012) \\
\hline Continuous improvement & 45 & Dayama and Jidugu (2009), Hamdi et al. (2014) \\
\hline$R \& D$ and innovation & 41 & Kasirian and Yusuff (2013), Ma and Liu (2011) \\
\hline Transportation and logistics & 39 & Opricovic (1998), Osman and Demirli (2009) \\
\hline Minimum and maximum order quantities & 32 & Pan et al. (2014), Saaty and Sagir (2009) \\
\hline Financial terms of the agreement & 31 & Wu et al. (2008), Schneider et al. (2009) \\
\hline Technical capabilities & 26 & Ren and Lin (2009), Ravindran et al. (2010) \\
\hline Strategic fit & 26 & Peng and Wang (2011), Qin et al. (2017) \\
\hline Impression & 24 & Omosigho and Omorogbe (2014) \\
\hline Attitude & 21 & Mian (2011), Kumaraswamy et al. (2011) \\
\hline Labor relations record & 19 & Karimi and Rezaenia (2014), Lima et al. (2013) \\
\hline Training aids & 18 & Shen et al. (2010), Yu and Wong (2014) \\
\hline
\end{tabular}

In summary, for any firm, supplier selection is a crucial decision-making process that directly affects purchasing and overall operations. Choosing the optimal suppliers enables a firm to remain competitive. While there is no ideal methodology, various approaches can be efficient depending on supplier selection setup and complexity. Also, as noted here, given the changing nature of the operations management domain, several emerging approaches are expected to contribute to the supplier selection literature.

\section{CONCLUDING REMARKS AND DIRECTIONS FOR FURTHER RESEARCH}


DOI: 10.14807/ijmp.v12i1.1265

Global competition, high customer expectations, and harsh economic conditions force companies to rely on external vendors and suppliers. Supplier selection is a strategic decision that requires companies to trade-off between multiple criteria, thereby creating ambiguity and imprecision. Over time, the complexity of supplier selection has significantly increased, and new methods have emerged for evaluating and selecting suppliers. Moreover, to overcome limitations inherent in single methods, integrated techniques are also being used to solve reallife problems.

This review of the supplier selection literature (from 1998 to 2018) included 170 articles that have applied a variety of approaches. The reviewed literature includes articles that have proposed individual methods, as well as articles reporting integrated techniques. Among those articles that applied a single method, AHP was most common. The simplicity and ease of use of AHP make it a valuable tool for researchers dealing with multi-criteria decision-making. It was also found that the most prevalent integrated approaches were based on FST.

These findings show that recent studies on supplier selection have placed much emphasis on overcoming the subjective and human factors inherent in supplier selection problems. In addition to the traditional approaches to supplier selection (individual and integrated), this review also identified a third category of articles: those applying nonconventional, emerging approaches (methodologies addressing specific supplier selection themes and aspects that have not yet been well-studied).

A strength of this review is that, after identifying and categorizing the published methods, their strengths and weaknesses have been investigated, while also analyzing the most prevalent attributes used by the various articles. To our knowledge, this is the first review article to address non-conventional approaches, such as market utility-based methods. Furthermore, we include an updated list of attributes with emerging supplier selection criteria used in recent studies.

Based on our findings, we conclude that there remains much opportunity for future work in the supplier selection domain. First, some of the existing prevalent methods (e.g., FST) could be developed further and tested on new data samples. A limited number of evaluation criteria are used for this method, and it should be possible to test a more comprehensive list of attributes. Furthermore, the membership functions and criterion importance and/or performance scale intervals are unchanged from one study to another. 
DOI: 10.14807/ijmp.v12i1.1265

Given that fuzzy logic can be applied based on other membership functions and importance/performance scales, it would be interesting to test those and compare the results across different model specifications. Also, most of the studies have examined the topic for automotive and assembly, chemical, or metal processing industries. Similarly, they have mainly developed case studies based on a single country or a region. These lists could be extended to test the proposed models among richer industry-country cohorts.

\section{ACKNOWLEDGEMENTS}

The author gratefully acknowledges the support of the International Visegrad Fund from the Visegrad Scholarship Program. The author wishes to thank Mikołaj Czajkowski for his advice and guidance.

\section{REFERENCES}

Amoako-Gyampah, K., \& Acquaah, M. (2008). Manufacturing strategy, competitive strategy and firm performance: An empirical study in a developing economy environment.

International Journal of Production Economics, 111(2), 575-592.

Basnet, C., \& Leung, J. M. Y. (2005). Inventory lot-sizing with supplier selection. Computers \& Operations Research, 32(1), 1-14.

Bhutta, K. S.; Huq, F. (2002). Supplier selection problem: A comparison of the total cost of ownership and analytical hierarchy process approaches. Supply Chain Management, 7, 126.

Cakravastia, A.; Takahashi, K. (2004). Integrated model for supplier selection and negotiation in a make-to-order environment. International Journal of Production Research, 42(21), 4457-4474.

Carter, C. R., \& Jennings, M. M. (2004). The role of purchasing in corporate social responsibility: A structural equation analysis. Journal of Business Logistics, 25(1), 145186.

Chan, F. T. S. (2003) Interactive selection model for supplier selection process: An analytical hierarchy process approach. International Journal of Production Research, 41(15), 35493579 .

Choy, K. L., Lee, W. B., \& Lo V. (2003). An intelligent supplier relationship management system for selecting and bench marking suppliers. International Journal of Technology Management, 26(7), 717-740.

Choy, K. L. et al. (2004). Design of an intelligent supplier relationship management system for new product development. International Journal of Computer Integrated Manufacturing, 17(8), 692-715.

Dickson, G. W. (1966). An analysis of vendor selection systems and decisions. Journal of Purchasing, 2(1), 5-17.

Ding, X., Verma, R., \& Iqbal, Z. (2007). Self-service technology and online financial service choice. International Journal of Service Industry Management, 18(3), 246-268. 
Eltantawy, R. A., Sharland, A., \& Giunipero, L. C. (2003). The impact of cycle time on supplier selection and subsequent performance outcomes. Journal of Supply Chain Management, 39(3), 4-12.

Gonzàlez, M. E., Quesada, G., \& Mora Monge, C. A. (2004). Determining the importance of the supplier selection process in manufacturing: A case study. International Journal of Physical Distribution \& Logistics Management, 34(6), 492-504.

Huang, S. H., \& Keskar, H. (2007). Comprehensive and configurable metrics for supplier selection. International Journal of Production Economics, 105(2), 510-523.

Ittner, C. D., \& Larcker, D. F. (1999). Supplier selection, monitoring practices, and firm performance. Journal of Accounting \& Public Policy, 18(3), 253-281.

Kannan, V. R., \& Tan, K. C. (2002). Supplier selection and assessment: Their impact on business performance. Journal of Supply Chain Management, 38(4), 11-23.

Kaplan, S., \& Sawhney, M. (2000). E-hubs: The new B2B marketplaces. Harvard Business Review, May-June, p. 97-103.

Yazdi, A. K. et al. (2018). Finding the Best Third-Party Logistics in the Automobile Industry: A Hybrid Approach. Mathematical Problems in Engineering

Karpak, B. et al. (1999). Multi-objective decision-making in supplier selection: An application of visual interactive goal programming. Journal of Applied Business Research, 15(2), 57-71.

Kaviani M. A. et al. (2019). An integrated grey-based multi-criteria decision-making approach for supplier evaluation and selection in the oil and gas industry. Kybernetes

Kumar et al. (2018). Construction of capital procurement decision making model to optimize supplier selection using Fuzzy Delphi and AHP-DEMATEL. Benchmarking: An International Journal, 25(5), 1528-1547.

Li, S. et al. (2006). Supplier-switching inertia and competitive asymmetry: A demand-side perspective. Decision Sciences, 37(4), 547-576.

Liao, C. N. (2010). Supplier selection project using an integrated Delphi, AHP and Taguchi loss function. ProbStat Forum, 3, 118-134.

Liao, Z., \& Rittscher, J. (2007a). A multi-objective supplier selection model under stochastic demand conditions. International Journal of Production Economics, 105(1), 150-159.

Liao, Z., \& Rittscher, J. (2007b). Integration of supplier selection, procurement lot sizing and carrier selection under dynamic demand conditions. International Journal of Production Economics, 107(2), 502-510.

Lin, C. et al. (2005). A structural equation model of supply chain quality management and organizational performance. International Journal of Production Economics, 96(3), 355365.

Masella, C., \& Rangone, A. (2000). A contingent approach to the design of vendor selection systems for different types of co-operative customer/supplier relationships. International Journal of Operations and Production Management, 21(1), 70-84.

Mckenna, H. P. (1994). The Delphi technique: a worthwhile research approach for nursing? Journal of Advanced Nursing, 19(6), 1221-1225. 
DOI: 10.14807/ijmp.v12i1.1265

Pullman, M. E., \& Moore, W. L. (1999). Optimal service design: Integrating marketing and operations perspectives. International Journal of Service Industry Management, 10(2), 23-26.

Pullman, M. E., Verma, R., \& Goodale, J. C. (2001). Service design and operations strategy formulation in multicultural markets. Journal of Operations Management, 19(2), 239-254.

Sarkis, J., \& Semple, J. (1999). Vendor selection with bundling: A comment. Decision Sciences, 30(1), 265-271.

Talluri, S., Narasimhan, R., \& Nari, A. (2006). Vendor performance with supply risk: A chance constrained DEA approach. International Journal of Production Economics, 100(2), 258-261.

Valluri, A., \& Croson, D. C. (2005). Agent learning in supplier selection models. Decision Support Systems, 39(2), 219-240.

Van Der Rhee, B., Verma, R., \& Plaschka, G. (2009). Understanding trade-offs in the supplier selection process: the role of flexibility, delivery, and value-added services/support. International Journal of Production Economics, 120(1), 30-41.

Verma, R., \& Pullman, M. E. (1998). An analysis of the supplier selection process. Omega, 26(6), 739-750.

Verma, R., Thompson, G. M., \& Louviere J. J. (1999). Configuring service operations in accordance with customer needs and preferences. Journal of Service Research, 1(3), 262274.

Verma, R. et al. (2001). Effective design of products/services: An approach based on integration of marketing and operations management decisions. Decision Sciences, 32(1), 165-193.

Vonderembse, M. A., \& Tracey, M. (1999). The impact of supplier selection criteria and supplier involvement on manufacturing performance. Journal of Supply Chain Management, 35(3), 33-39.

Wang, G., Huang, S. H., \& Dismukes, J. P. (2004). Product-driven supply chain selection using integrated multi-criteria decision-making methodology. International Journal of Production Economics, 91(1), 1-15. 